\title{
Challenges Faced By Security Personnel in Fraud Detection in the County Government of Nairobi, Kenya
}

\author{
Fredrick Okoth Otieno ${ }^{1}$, Dr. Esther Chelule ${ }^{2}$, Dr. Erick K. Bor ${ }^{3}$ \\ ${ }^{1}$ Post Graduate Scholar, Department of Peace, Security \& Social Studies, Egerton University, Kenya \\ ${ }^{2}$ Lecturer, Department of Peace, Security \& Social Studies, Egerton University, Kenya \\ ${ }^{3}$ Lecturer and Consultant, Department of Peace, Security \& Social Studies, Egerton University, Kenya
}

\begin{abstract}
The County Government of Nairobi security personnel has not been able to convincingly prevent fraud from taking place. Fraud as a vice has continued to thrive even with their heavy presence there. Funds that would have otherwise been used for growth and development are lost to fraudsters. This is because of the numerous challenges they face in fraud detection that hamper their operation. Thestudy therefore sought toestablish the challenges faced by security personnel in fraud detection in the County Government of Nairobi. Social Learning and Rational Choice theories were employed in explaining the behaviour of individuals who commit fraud. The study further assessed the various indicators used by security personnel in fraud detection as well as the various categories of fraud committed in the County Government of Nairobi.
\end{abstract}

Keywords:Challenges, County Government, Detection, Fraud, Security Personnel, Kenya.

\section{Introduction}

Pricewaterhouse Coppers Report on Corruption revealed that the former County Council of Nairobi looses $7.5 \%$ of its annual revenue to fraud which translates to 25 million [1]. The report further projected that this kind of loss incurred in relation to the Gross Domestic Products is estimated at about 3.1 billion. Such estimates give a perception of the extent of the losses that the County Government of Nairobi suffers. Given such huge figures, the City Inspectorate Department need to go back to the drawing board. They need to establish why there is much investment in overall physical and financial security but still there is high prevalence in fraud cases and huge losses incurred.

Security personnel in the County Government of Nairobi are, among others duties, charged with the task of ensuring that the County Government of Nairobi by-laws are adhered to through maintenance of law and order, protection of property, apprehension of offenders and detection \& prevention of crime. They investigate fraud cases with the aim of bringing the culprits to book and deterring potential offenders. This ensures that revenue is regularly collected and various allocations are used effectively as planned, hence does not end up in the hands of unscrupulous individuals [2].

In spite of these roles, there is continued prevalence and increase in reported cases of fraud [1]. The County Government of Nairobi security personnel has not been able to convincingly prevent fraud from taking place. Fraud as a vice has continued to thrive even with their heavy presence there. Funds that would have otherwise been used for growth and development are lost [1]. This has been occasioned by various challenges the face in fraud detection. The research therefore established the challenges faced by researchers in their duty of fraud detection. Am hopeful that the data collected and findings will help shape fraud detection by giving insights which points towards easier detection and deterrence, help overcome the challenges in fraud detection as well as providing a basis for future research on fraud and modern crime analysis in organisations. It will also contribute to the existing body of knowledge.

\section{Literature Review}

Fraud has varying dimension in society. Corruption refers to a scheme in which fraudsters use their influence in business transactions in a way that violates their duty to the employers in order to benefit themselves or someone else. Examples include bribes, extortions, and conflicts of interest. Fraud is defined as, 'the crime of obtaining money from someone by tricking them or the action of producing false documents or information in order to get what you want" [3].Thus the identification of fraud in our institutions is dependent on various issues surrounding the crime itself [4].

Fraud has three major precepts; asset misappropriation, corruption and financial statement. Asset misappropriations are frauds in which the perpetrator steals or misuses organisation's resources. They include skimming and cash larceny, frauds involving fraudulent disbursement of cash like billing, cheque tampering, expenses reimbursement, payroll inflation, tempering with cash register and assets misappropriation like cash on 
hand misappropriation \& non cash appropriation [5]. The three major precepts can however only be linked to a formal employment setup.

Corruption is defined as the misuse of public power, office or authority for private benefit [6]. Financial statement fraud involves the misstatement or omission of material information from the organisation's financial reports. Example of some of these frauds involves reporting of fictitious revenues or the concealment of expenses or liabilities in order to make an organisation appear profitable than it really is.

Sub Saharan African countries list corruption as one of many hindrances towards their growth and development.Corruption is a regressive tax that must be addressed. The marginalised and the poor remains the most vulnerable to extortion. Government should do more to identify corruption risks in basic services and protect their citizens from exploitation [7].

Other irregular activities that employees engage in for their own benefit include, acceptance of kickbacks and bribes, intentional concealment or misrepresentation of events transactions or data, claims submitted for services or goods not actually provided to the organisation, intentional failure to act in circumstances when action is required by the company or by the law, unauthorised or illegal use of confidential, proprietary information, and unauthorised or illegal manipulation of information technology networks or operating system [5].

A comprehensive understanding of fraud will help in identification of various dynamics and dimensions of fraud in the present world. Different people perceive fraud differently. Corruption is 'oil or sand' to mean that it can either speed up the bureaucratic processes or long term corruption transactions raises unnecessary transactions costs and leads to inefficient economic outcomes respectively [8]. This gives a mixed feeling of the concepts and further studies to prove either side are justified.

There are two major causes of fraud; personal (perpetrators) characteristics and organizational environment. Personal (perpetrators) characteristics; living beyond their means, an overwhelming desire for personal gain, high personal debt, a close association with customers, feeling pay was not commensurate with responsibility, a wheeler dealer attitude, strong challenge to beat the system, excessive gambling attitude, undue family or peer pressure, and no recognition for job performance [9].

Secondly, Organisational environment; placing too much trust in key employees, lack of proper procedure for authorities of transaction, inadequate disclosures of personal investment and incomes, no separation of authorization of transactions from the custody of related assets, lack of independent checks on performance, inadequate attention to details, lack of separation of custody of assets from the accounting for those assets, no separation of duties between accounting functions, lack of clear lines of authority and responsibility and department that is not frequently reviewed by auditors [9].

Albrecht summarised his study by stating that “...it appears that three elements must be present for fraud to be committed; a situational pressure (non-shareable financial pressure), a perceived opportunity to commit ... and some way to rationalise the act as either being inconsistent with one's personal level of integrity or justifiable.

Perceived Opportunity

Pressure

Figure 2.1: Donald Cressey's Fraud Triangle.

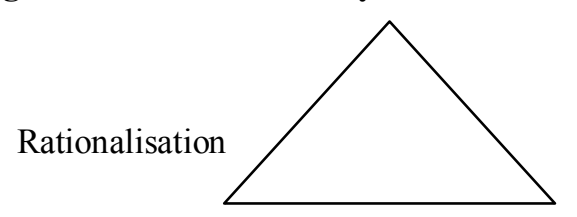

Source: ACFE Report, 2010

Different motivations lead individuals to committing fraud; however the environment in which the individuals are operating in could highly contribute to fraud commission. Trusted persons become violators when they conceive of themselves as having a financial problem which is non-shareable .... and are able to apply their own conduct in that situation verbalisations which enable them to adjust their conceptions of themselves as trusted persons...'[10]. The proposition was later to be developed to the fraud triangle shown in Figure 2.1 above indicating the three major factors causing fraud i.e. pressure, opportunity and rationalisation.

Perceived opportunity is the conviction that you can steal or is in a position of fiduciary duty, or that trustworthy position can be violated. When persons in authority can create opportunity to override existing controls because of subordinate or weak controls allowing them to navigate through the set rules, then the institutions is at great fraud risk.

Pressure, also referred to as motive, incentive or non-shareable financial needs, is the gratification for a desire, greed or an addiction that tends to generate a pressure from within or without and what result is as an immense drive to do anything at your capacity to achieve your goals [3]. 
Rationalisation is that aspect of convincing oneself that what you do is still good. Others tend to see it as a general irresponsibility for which you are not accountable. The discussion of factors promoting fraud has been reviewed from time to time due to the evolution of fraud tactics. However studies done so far have only linked these three factors as the major categories of fraud causes.

\section{Methodology}

The study involved the County Government of Nairobi City Inspectorate Department as the target population. The study employed non probability stratified random sampling and purposive sampling techniques to arrive at a sample of 68 respondents. However, only 58 respondents were interviewed as the remainders were either on leave or on assignment outside Nairobi during the entire data collection period. Primary data was collected through interview schedule administered to the respondents to provide data for both quantitative and descriptive data analysis. Interview schedule was useful in this study since the topic under research, fraud, is sensitive and some respondents could have shied off from answering certain questions. By directly administering the questions to the respondents, the researcher was able to seek clarification on grey areas and avoided non response that may have arose if another research tool other than interview schedule was employed.Data obtained from the interview schedules was processed through cleaning and editing and entering them into the computer system for analysis using descriptive statistics with the help of SPSS version which offers numerous statistical analysis procedures. The analysed data was presented using tables and graphic representation of frequency distribution (histogram and charts).

\section{Results}

The research findings in this chapter strived to answer the research questions as well as meeting the research objectives. The figures, percentages and frequencies used in this chapter and the next one refer to the entire sample unless stated otherwise.

\subsection{Fraud Indicators used by Security Personnel in Fraud Detection}

The first specific objective of this study was to assess the various fraud indicators used by security personnel in fraud detection in the County Government of Nairobi. Findings revealed that the highest used fraud indicator was weak internal control $(26.52 \%)$. The weak internal control used by security personnel in fraud detection included lack of proper supervision, absence of rules and regulation governing job performance, obscure job description, cronyism \& patronage and ceremonial chain of command. Sudden behavior change accounted for $22.10 \%$. The noticeable behavior changes included working alone, deceitfulness, extended working hours, withdrawal syndrome, frequent calls in coded language, being cosy with clients and uneasiness with colleagues. $19.34 \%$ showed indication that people who committed fraud exhibited some personal problem such as depression, isolation, lack of motivation, nervousness, withdrawal from other staff and self suspicion. $20.44 \%$ indicated poor book keeping as fraud indicator. Poor book keeping practices included absence of certain entries, erasures, crossings, missing/plucked leaves, non-reconciling entries, un-inspected receipt books and other financial records and missing copies of financial transactions. 11.60\% reported expensive living standard as fraud indicator which included living beyond ones means, buying expensive suits, cars, palatial residences, gifts beyond ones known sources of income, making frequent expensive trips and overspending. This information is indicated in TABLE 1 below.

Table 1.Fraud Indicators used by Security Personnel in Fraud Detection

\begin{tabular}{lccc}
\hline Indicator & Frequency & Percentage & \\
\hline & & 26.52 & \\
Weak internal control & 96 & & 22.10 \\
Sudden behavior change & 80 & 20.44 & \\
Poor book keeping & 74 & 19.34 & \\
Personal problem & 70 & 11.60 & \\
Expensive living standard & 42 & 100.00 \\
\hline Total & 362 & \\
\hline
\end{tabular}

Source: Data obtained from research, 2014

\subsection{Categories of Fraud Committed in the County Government of Nairobi}

The second specific objective was to examine the various categories of fraud committed in the County Government of Nairobi. Fraud, a generic term used to describe any deliberate act to deceive or mislead another person, carry harm or injury, was differentiated from the findings collected and categorized in two ways, the first, depending on classes of perpetrators hence internal versus external fraud and the second one based on the types of fraud committed 


\subsubsection{Internal Fraud versus External Fraud Category}

In this category, $65.29 \%$ indicated that internal fraud is the type of fraud committed in the County Government of Nairobi while $34.71 \%$ indicated external fraud. In this category, fraud is external when the victim is external to the organisation and internal if otherwise. Fraud committed by employees, internal auditors, executives is internal fraud. Fraud committed by external parties e.g. investors, suppliers, customers, and external auditors is known as external fraud.

\subsubsection{Categorisation by Type of Fraud Committed}

In this category, fraud has five (5) sub categories: bribery i.e. extortion and receipt of illegal gratuities, asset misappropriation i.e. theft of cash inventory, overpaying employees, paying ghost workers, payroll inflation, tampering with cash register/cheque, skimming and billing, financial statement fraud i.e. altering financial records, material omission/misrepresentation, fictitious revenues, deliberate misapplication and concealed liabilities/expenses, disclosure fraud i.e. incomplete disclosures, improper disclosures, omissions, misrepresentation of information presented in notesand lastly liability \& revenue fraud (overstating asset fraud) i.e. overstating purchases, returns $\&$ allowances, not recording purchases, understating liabilities, overstating assets, overstating cash.

Bribery at $41.86 \%$ is the most committed fraud sub category followed by asset misappropriation at $34.42 \%$, financial statement fraud at $10.23 \%$, liability and revenue fraud at $8.37 \%$ and disclosure fraud at $5.12 \%$. It is apparent that internal fraud (65.29\%), bribery (41.86\%) and asset misappropriation (34.42\%), which are all time high, are the sub categories of fraud that poses a challenge to security personnel in their fight against fraud in the County Government of Nairobi. This information is summarized in TABLE 2 below.

Table 2. Percentage of Type of Fraud Committed

\begin{tabular}{lrlrr}
\hline Fraud Sub Category & \multicolumn{3}{c}{ Frequency } & Percentage \\
\hline Bribery & & 90 & 41.86 & \\
Asset misappropriation & 74 & & 34.42 & \\
Financial statement fraud & 22 & & 10.23 & \\
Disclosure fraud & 11 & 5.12 & \\
Liability and revenue fraud & 18 & 8.37 & 100.00 \\
\hline Total & 215 & & \\
\hline
\end{tabular}

\section{Source: Data obtained from research, 2014}

\subsection{Challenges Faced by Security Personnel in the County Government of Nairobi}

The third specific objective was to establish the challenges faced by security personnel in the County Government of Nairobi. The responses from the respondents were clustered into five categories as listed in TABLE 3 below. It is important to note that a number of respondents gave general challenges they face but not limited to fraud detection. This is because in one way or the other, even the general challenges contribute in their ability to detect fraud. These categories were analysed thereafter from the responses in the interviews held. $32.76 \%$ indicate salary related issues. Salary related issues included non-payment of minimum wage, no payment for working overtime, delayed payment of salary, irregular dates of payment, unathorised deductions, and unreliable system of regular salary increment. $27.99 \%$ indicated poor working condition. These included working overtime, no lunch and breakfast, long working hours, working odd hours, long hours of continuous standing, limited leaves of absence e.g. sick leave, maternity leave, off duty, annual leave etc. lack of provision for counseling services, dissimilarity in condition of work and inadequate working tools and equipments including uniform and first aid kits. $26.28 \%$ indicated management issues as the challenges they face in fraud detection. Management issues included favoritism, tribalism, nepotism, ghost employment, unqualified employees, non-review/weak internal control, improper oversight, absence of proper audit, complex organizational structure and lack of proper in service training opportunities. $6.83 \%$ indicated social security issues. These included improper medical cover, low provident funds, non-existent sickness benefits and improper medical benefits. $6.14 \%$ fall under Others. These included lack of proof of employment, misbehavior by employees, unsuitable climatic conditions, job insecurity, monotony and boredom in performing duty and at place of work.

Table 3. Challenges Faced by Security Personnel in the County Government of Nairobi

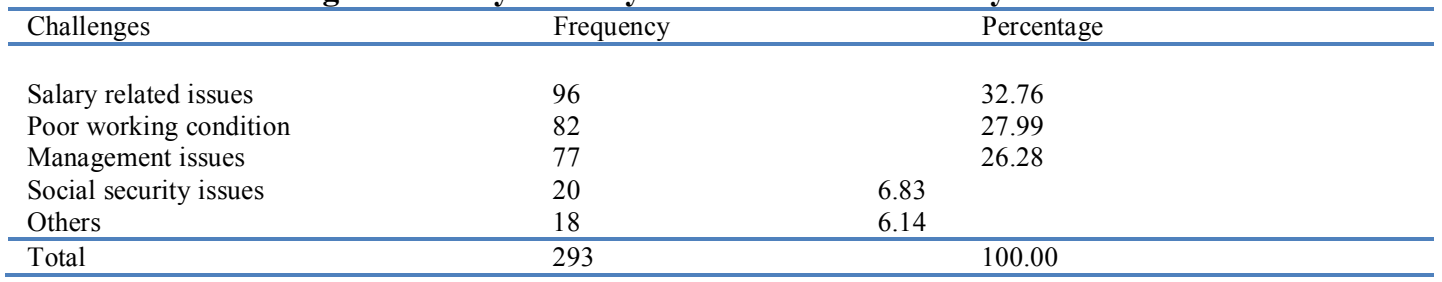

Source: Data obtained from research, 2014 


\subsection{Ways of Dealing with the Challenges Faced by Security Personnel in Fraud Detection}

Though not part of research objectives, the study explored ways of dealing with the challenges faced by security personnel in fraud detection. The responses from the respondents were clustered into two major categories. $65.70 \%$ indicated good personnel policies and procedures. The major strategies listed were adequate remuneration levels, payment for work done overtime, regular pay and pay increment, improving social security and welfare of workers e.g. rewards for good work done and provision of breakfast, staff development programmes including staff appraisal, staff rotation, thorough screening during recruitment process, ensuring staff goes for their various leaves promptly, prompt provision of various benefits e.g. medical cover, provision of working equipments e.g. uniforms, conducting exit interviews to obtain feedback and good working condition.

$34.30 \%$ indicated adequate internal control. The major issues listed were thorough supervision and periodic reconciliation of books of account, management control, authorization of transactions, physical controls, segregation of duties, developing clear lines of responsibility, selecting, training and appraising qualified personnel, bringing on board regular auditors, eliminating nepotism and tribalism and stern action being taken against fraudsters.

\section{Conclusion and Recommendations}

From the findings, it is evident that the indicators used in the County Government of Nairobi by security personnel in fraud detection fall in five categories as follows: The first is weak internal control,sudden behavior changes, poor book keeping, personal problems and expensive living standards. Weak internal control is thus the most used indicator thus a major challenge. The County Government of Nairobi need to tighten its internal control to ensure fraud does not occur since, as explained by social learning theory, individuals inheriting weak internal control will learn from their predecessors hence engage in the same and allow fraud to thrive.

Further, two categories of fraud; the first, depending on classes of perpetrators i.e. internal fraud versus external fraud and the second one based on the types of fraud committed were established. In the second category, based on the types of fraud committed, 5 sub categories were established i.e. bribery,asset misappropriation, financial statement fraud, liability and revenue fraud and disclosure fraud. It is therefore apparent that from the two categories, internal fraud and bribery, which are all time high in the County Government of Nairobi poses a major challenge to security personnel hence the need to eradicate them.

The challenges faced by security personnel were general and not necessarily restricted to fraud detection alone. They were five fold: salary related issues, poor working, management issues, social security issues and others. It was found out that these challenges can be dealt with by initiating proper personnel policies and procedures and initiating adequate internal control. These when put in place can ensure fraud is eradicated.

Suggestions that may help in dealing with the challenges faced by security personnel in fraud detection in the County Government of Nairobi are:

The County Government of Nairobi should proactively employ the use of fraud indicators in fraud detection and prevention.

The County Government of Nairobi should come up with fraud detection and prevention strategy which should be focused mainly on bribery and internal fraud sub categories.

The County Government of Nairobi should address various challenges faced by security personnel in the County Government of Nairobi to enhance fraud detection and prevention. In particular the government should address salary related issues, working condition issues, management issues and social security issues.

The County Government of Nairobi needs to be proactive in fraud education, awareness, examination, audit and surveillance. They should regularly hold workshops for sensitization and sharing of information and intelligence on fraud to improve on their detection procedures. If need be, they should source for and bring on board resource persons from other related agencies.

The County Government of Nairobi should know their employees right from recruitment, through wealth declaration policies, proper employee monitoring and employee feedback. There is need to establish proper reporting mechanism to encourage fraud reporting such as fraud hotlines.

The County Government of Nairobi needs to streamline fraud detection procedure as well as invest in training of their security personnel on fraud detection and prevention techniques. Further studies on emerging issues and trends on fraud would help in advancement of knowledge in fraud indicators. Fraudsters keep changing tact once their tactics are discovered hence to keep abreast there is need for doing research on emerging fraud trends. 


\section{References}

[1] Pricewaterhouse Coppers Report on Corruption, Kenya (2011)

[2] City Inspectorate Regulations, (2003)

[3] Macmillan English Dictionary for Advanced Learners, $2^{\text {nd }}$ Edition, London, (2007)

[4] Albrecht, S. (1984). Deterring Fraud; The Internal Auditor's Perspective. Baltimore Springs: The Institute of Internal Auditors Research Foundation.

[5] Association of Certified Fraud Examiners Report to the Nations, (2012)

[6] Abigail, M. (2001). Axle Load Control Management Report, Kenya: Nairobi, Kenya Anti Corruption Commission.

[7] Hugutte, I. (2008). Transparency International.www.transparency.org/news room

[8] Gary, C. \& Kaufmann, D. (1998). Corruption and Development, Finance and Development, Vol. 35, No. 1. London, Sage Publication.

[9] Albrecht, S. (2003). Fraud Examination. OH, South Western Thomson.

[10] Cressey, D. (1973). Other People's Money; A study in the Social Psychology of Embezzlement. Montclair: Patterson Smith. 